\title{
SPECTRAL F-TEST POWER EVALUATION IN THE EEG DURING INTERMITTENT PHOTIC STIMULATION
}

\author{
Antonio Mauricio F. L. Miranda de Sá1, Mauricio Cagy², \\ Vladimir V. Lazarev³, Antonio Fernando C. Infantosi4
}

\begin{abstract}
Intermittent photic stimulation (IPS) is an important functional test, which can induce the photic driving in the electroencephalogram (EEG). It is capable of enhancing latent oscillation's manifestations not present in the resting EEG. However, for adequate quantitative evaluation of the photic driving, these changes should be assessed on a statistical basis. With this aim, the sampling distribution of spectral F test was investigated. On this basis, confidence limits of the SFT-estimate could be obtained for different practical situations, in which the signal-to-noise ratio and the number of epochs used in the estimation may vary. The technique was applied to the EEG of 10 normal subjects during IPS, and allowed detecting responses not only at the fundamental IPS frequency but also at higher harmonics. It also permitted to assess the strength of the photic driving responses and to compare them in different derivations and in different subjects.
\end{abstract}

KEY WORDS: EEG, intermittent photic stimulation, photic driving, Spectral $F$ test, quantitative analysis.

\section{Avaliação do teste-F espectral do EEG durante fotoestimulação intermitente}

RESUMO - A fotoestimulação intermitente (FEI) é um importante teste functional, que pode induzir o fotorecrutamento no eletroencefalograma (EEG), sendo capaz de realçar manifestações latentes de oscilações não observadas no EEG de repouso. Entretanto, para uma análise quantitativa adequada do fotorecrutamento, tais alterações devem ser avaliadas com base estatística. Assim, a distribuição de probabilidade do teste-F espectral (TFE) foi investigada. Neste sentido, limites de confiança para a estimativa do TFE puderam ser obtidos para diferentes situações práticas, nas quais a razão sinal-ruído e o número de épocas usadas na estimação podem variar. A técnica foi aplicada ao EEG de 10 sujeitos normais durante FEl, e permitiu a detecção de respostas não somente na freqüência fundamental da FEl como também em seus harmônicos. Além disso, permitiu avaliar o grau de fotorecrutamento entre derivações distintas e entre diferentes sujeitos.

PALAVRAS-CHAVE: EEG, fotoestimulação intermitente, fotore crutamento, teste-F espectral, análise quantitativa.

Inte rmittent photic stimulation (IPS) is considere d as one of the most important functional neurophysiological tests that can induce photic driving in the electroencephalogram (EEG). It is capable of enhancing the latent oscillations' manifestation including pathological alterations, which are not observable in the EEG of the resting state ${ }^{1-4}$. However, for an adequate quantitative evaluation of the photic driving these changes should be assessed on a statistical basis ${ }^{5}$.

Spectral F-Test (SFT) is a statistical test for assessing whether two sample spectra are from populations with identical theoretical spectra, and has been applied in objectively detecting somatosensory ${ }^{6}$ and a uditoryevoked re spon se $\mathrm{s}^{7}$. It can be applied either to investigate two diff e rent spectral estimates over the same frequency band or to test samples from the same spectral density over two diffe rent frequency bands ${ }^{8}$. On this basis, SFT was applied to the EEG during IPS and showed to be sensitive in detecting spectral changes related to the stimulation ${ }^{4}$. SFT allows ascertaining whether photic driving occurs according to statistical criteria. Since SFT sampling distribution is known under the null hypothesis of same theo retical spectra $\left(\mathrm{H}_{0}\right)$, critical values can be readily ob-

\footnotetext{
'D.Sc., Professor Adjunto, Programa de Engenharia Biomédica (PEB) - COPPE, Universidade Federal do Rio de Janeiro, Rio de Janeiro RJ, Brasil (UFRJ); ${ }^{2}$ D.Sc., Pesquisador, PEB - COPPE / UFRJ; ${ }^{3}$ Ph.D., Professor Titular, Laboratório de Neurobiologia e Neurofisiologia Clínica, Instituto Fernandes Figueira, FIOCRUZ, Rio de Janeiro; ${ }^{4}$ Ph.D., Professor Titular, PEB - COPPE / UFRJ. This work received financial support from the Brazilian Research Agency (CNPq) and the Rio de Janeiro State Research Foundation (FAPERJ).
}

Received 26 July 2005, received in final form 21 October 2005. Accepted 24 November 2005. 
tained. They constitute thresholds above which statistical difference between the estimates can be accepted.

However, in order to evaluate the power of SFT, i.e. the probability of correctly identifying spectral diffe rences (previous and during IPS), its sampling distribution should be investigated for the altern ative hypothesis $\left(\mathrm{H}_{1}\right)^{9}$. Furthermore, on the basis of such distribution, the strength of the EEG driving response to the stimulation could be compared (e.g. through the confidence limits) in diff e rent cortical regions as well as in diffe rent subjects including patients versus control group. Thus, the investigation of the sampling distribution of SFT under $\mathrm{H}_{1}$ would broaden the applicability of the technique to the EEG during IPS. This issue is exploited in the present work, where the power of SFT is assessed theoretically. The methodology proposed was applied to the EEG of normal subjects during IPS.

\section{METHOD}

The spectral $\mathrm{F}$ test (SFT) for the discrete-time signals $y[k]$ ( $h$ e re assumed to re $p$ resent an EEG lead during interm ittent stimulation) and $x[k]$ (EEG signal immediately before stimulation) can be defined $a s^{8}$.

$$
\hat{\phi}_{y x}(f)=\frac{\sum_{i=1}^{M}\left|Y_{j}(f)\right|^{2}}{\sum_{j=1}^{M}\left|X_{j}(f)\right|^{2}}
$$

where $f$ is the frequency index, " $\wedge$ " superscript denotes estimation, and $X i(f)$ and $Y i(f)$, a re, respectively, the Fourier Transform of the $i^{\text {th }}$ epoch of $x[k]$ and $y[k]$, which have been partitioned into $M$ disjoint segments each for carrying out the spectral estimation.

The case when no driving response occurs in the EEG leads $x[k]$ and $y[k]$ to be independent, Gaussian-distributed signals pertaining to populations with same theoretical spectra. This reflects the null hypothesis $\mathrm{H}_{0}$, under which $\hat{\phi}_{x x}(f)$ is known to be distributed as ${ }^{8}$

$$
\left.\hat{\phi}_{M X}(f)\right|_{H_{1}} \backsim F_{2 K 2 M}
$$

where $F 2 M, 2 M$ is the $\mathrm{F}$ - (Fisher) distribution with $2 M$ and $2 M$ degrees of freedom. Thus, for a given significance level if $\hat{\phi}_{m}(f)$ is greater than the critical value of the F-distribution in (2) the hypothesis of absence of cortical response can be rejected.

Nevertheless, one cannot ascertain that the driving re sponse has indeed occurred. This can be tested by using the alterrative hypothesis $\left(H_{1}\right)$ of presence of the driving response. In this case, the numerator of (1) is now the response but added to the spontaneous EEG. Hence, the F distribu- tion in (2) should be altered (not proved here) and the sampling distribution of $\hat{\phi}_{\bar{\gamma}}(f)$ under $\mathrm{H} 1$ can be expressed as:

where $F_{2 K S 2 M}$ is non-central $\mathrm{F}$ distribution, $\lambda$ is the noncentrality parameter (SNR is the signal-to-noise ratio). A complete proof of $\lambda$ exp ression is provided in ${ }^{10}$. It can be also derived with some further manipulations on the classical results of Akaike ${ }^{11}$ and Brillinger ${ }^{12}$.

$$
\left.\hat{\phi}_{y x}(f)\right|_{H_{1}} \sim F_{2 M 2 M}^{\prime}(\lambda=2 M \cdot S N R)
$$

In order to evaluate the performance of SFT in detecting driving responses, the power of the test should be established for distinct experimental conditions, i.e., diff e re $\mathrm{nt}$ $M$ and SNR values. The probability of detection (PD) is the a rea under the distribution of $\hat{\phi}_{\pi \mathrm{K}}(f)$ when response occurs (expression 3 ) for abscise values greater than the threshold for the detection (critical value for testing the absence of response, expression 2). This process is illustrated in Figure 1A for $M=24$ epochs, where PD is the shaded a rea. As can be noted, SNR $=2$ results in PD-value greater than that for $S N R=1$. Figure $1 B$ displays $P D$ for different number of epochs ( $M=6,12,24,48$ and 96 ) as a monotonically increasing function of SNR. It can be observed that if SNR is fixed, PD increases as $M$ is augmented. The SNR-values that provide $95 \%$ of detection are also indicated by arrows. The PD behaviour with M and SNR is due to the fact that the non-central $F$ distribution is shifted to the right as $\lambda(=2 M$.SNR) increases, leading to greater probability of detecting responses. This can be easily seen in Fig $1 \mathrm{~A}$.

EEG data collection and pre-processing - The SFT was applied to EEG signals obtained from 10 normal childre $n$ and adolescents (age range: 3-17 years) with no symptoms of neurological pathology and with normal visual evoked potential. None of them had a history of neurological, psychiatric or drug related illness. The local ethics committee approved this research.

EEG signals were recorded during a state of relaxed wakefulness (initial background, 2-3 min duration) and then over a period of 20-30 seconds during flash stimulation at the frequency of $6 \mathrm{~Hz}$. The subjects kept eyes closed throughout the examination. The multichannel EEG was acquired using the Nihon Kohden polygraph (EEG-4418) with $0.3 \mathrm{~s}$ time constant, $70 \mathrm{~Hz}$ high frequency filter (anti-aliasing) and $15 \mu \mathrm{V} / \mathrm{mm}$ sensitivity. Fourteen scalp m onopolar derivations (according to the International 10/20 System) with unilaterateral refe rences to the corresponding earlobes were utilized in the EEG recording. In the present study, only symmetrical occipital $\left(\mathrm{O}_{1}\right.$ and $\left.\mathrm{O}_{2}\right)$ and parietal $\left(\mathrm{P}_{3}\right.$ and $\mathrm{P}_{4}$ ) leads were used. The instants of the stimulation signal were also acquired in a separate channel in order to be used as a refe rence when applying the signal processing techniques.

The EEG signals digitized at a sampling frequency of $256 \mathrm{~Hz}$, before and during stimulation, were sectioned into $M=10$ epochs of equal duration ( $2 \mathrm{~s}$ ). The power-spectra of the EEG before and during stimulation were estimated using the periodogram of Bartlett based on the Discrete 


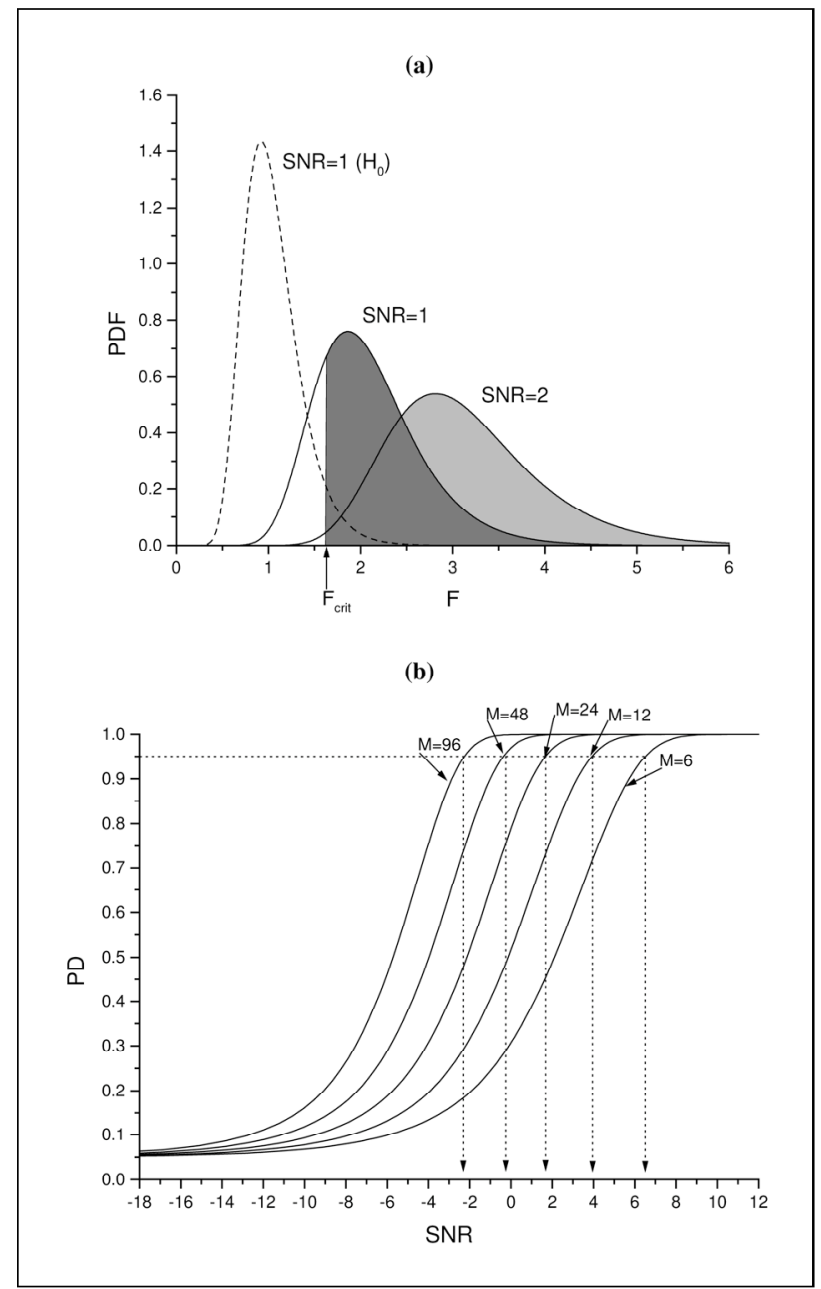

Fig 1. A) Illustration of the PD calculation as the shaded areas under the probability density function (PDF) of the non-cen tral F-distribution defined in expression (3) (continuous line) for $M=24$ and for both SNR=1 (dark grey-shaded area) and SNR= 2 (light grey-shaded area). The distribution under the nullhypothesis of no response $\left(H_{0}\right)$ is also shown for $M=24$ in dashed line. The critical value from this latter ( $F_{\text {crit }}$ - indicated by an a rrow) is taken as the inferior limit for the integral evaluation, which results in the shaded area. B) Probability of detection $(P D)$ with $\hat{\phi}_{y x}(f)$ as a function of the signal-to-noise ratio (SNR expressed in $d B$, i.e. $\left.(S N R)_{d B}=10 \bullet \log (S N R)\right)$ for diffe rent number of epochs ( $M=6,12,24,48$ and 96). SNR-values that lead to $95 \%$ expected detection rate are indicated by arrows.

Fourier Transformof the $2 \mathrm{~s}$ duration epochs (frequency resolution of $0.5 \mathrm{~Hz}$ ). The SFT was calculated using the EEG power-spectrum during stimulation in the numerator of exp ression (1) and that of the EEG before stimulation, in the denominator ${ }^{13}$. The critical value for the null hypothesis of absence of response was determined by setting a $5 \%$ percentage of significance $(\alpha)$ in the sampling distribution of (2). This leads to critical value for $\hat{\phi}_{\mathrm{p}}(f)$ equal to $2.12^{13}$. In order to test the alternative hypothesis $\left(\mathrm{H}_{1}\right)$ of the presence of a driving response, based on (3) the confidence limits $(95 \%)$ were determined.

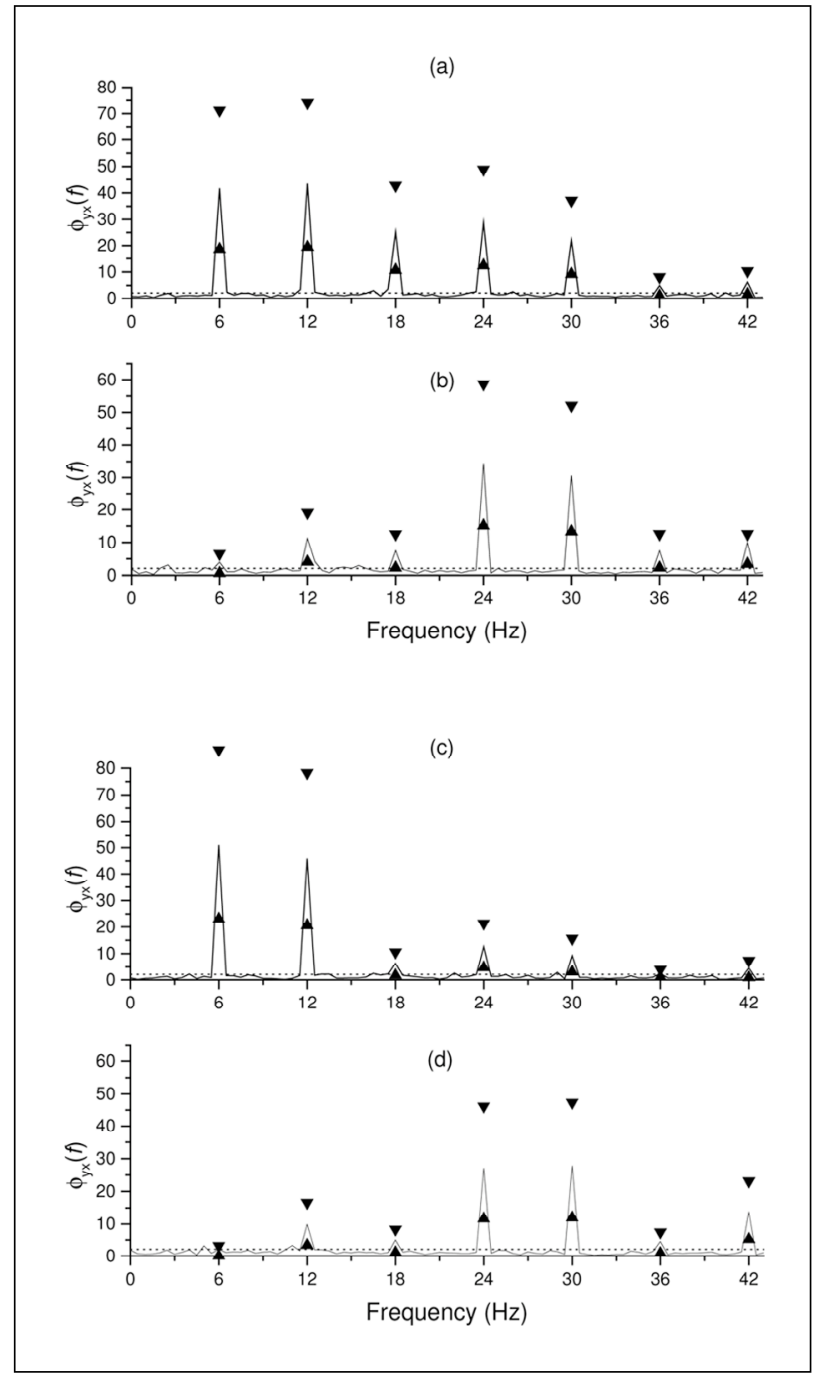

Fig 2. $\hat{\phi}_{y x}(f)$ (obtained according to expression (1) with $M=10$ epochs) for subject \#8 stimulated with stroboscopic flash at 6 $\mathrm{Hz}$ in the derivations: A) O1, B) P3, C) $\mathrm{O}_{2}$ and D) P4. The criti cal value $(\alpha=5 \%)$ is shown in horizontal dotted lines. It consti tutes a threshold upon which the driving responses can be assu med to have occurred. The $95 \%$ confidence limits for such res ponses are indicated with triangles.

\section{RESULTS}

Figure 2 illustrates the application of the SFT technique to the EEG from subject \#8. It can be noted in both occipital and parietal leads that $\hat{\phi}_{\pi}(f)$ exceeds the critical value (shown as a horizontal dotted line) at the stimulus frequency $(6 \mathrm{~Hz})$ and harmonics, even in the beta- 2 and in the lower gamma bands. In addition, the responses, as measured by $\hat{\phi}_{\pi}(f)$, are stronger in $\mathrm{O}_{1}\left(\mathrm{O}_{2}\right)$ than in $\mathrm{P}_{3}\left(\mathrm{P}_{4}\right)$, which is in accordance with the literature on the EEG photic driving ${ }^{2,4}$. Such diffe rences can be assessed through the comparison of the $95 \%$ confidence limits (indicated with triangles), which also indicate that the strength of the EEG 


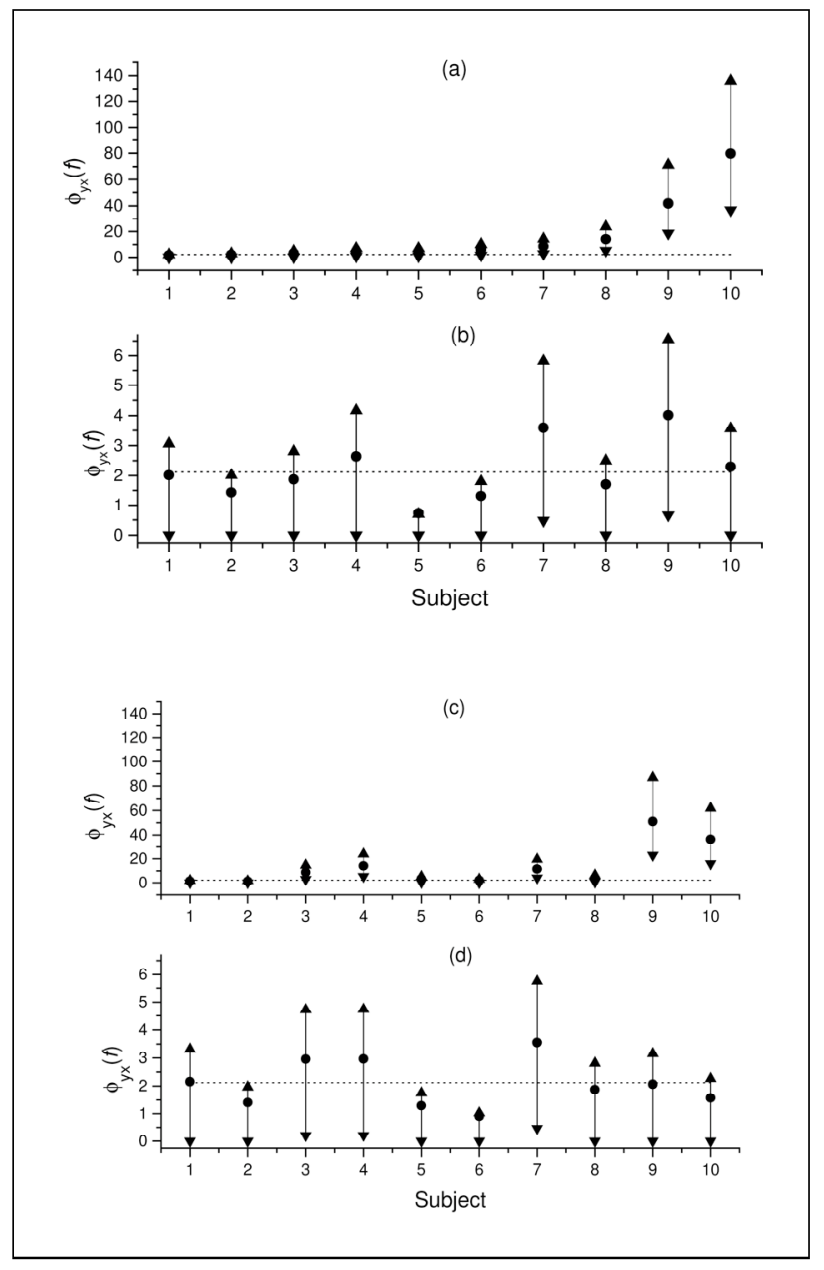

Fig 3. $\hat{\phi}_{m}(f)$ (obtained according to expression (1) with $M=10$ epochs) at the frequency of stimulation $(6 \mathrm{~Hz})$ is indicated by a circle and the $95 \%$ confidence limits are indicated with tri angles for each of the subjects in the derivations: A) O1, B) P3, C) $\mathrm{O}_{2}$ and D) P4. Critical values $(\alpha=5 \%)$ are shown in horizon tal dotted lines.

driving response at 6 and $12 \mathrm{~Hz}$ in $\mathrm{O}_{1}\left(\mathrm{O}_{2}\right)$ are significantly higher than those at 36 and $42 \mathrm{~Hz}$. On the other hand, for derivation $\mathrm{P}_{3}\left(\mathrm{P}_{4}\right)$ the strongest driving response occurs at 24 and $30 \mathrm{~Hz}$.

In Figure $3 \hat{\phi}_{7 x}(f)$, is depicted for the first harmonic of the stimulation frequency of $6 \mathrm{~Hz}$ in both occipital and parietal leads for all 10 subjects. It can be noted that there are substantial diff e rences in detecting response $\left(\hat{\phi}_{\mu x}(f)>2.12\right)$ between occipital and parietal leads. While $\mathrm{O}_{1}\left(\mathrm{O}_{2}\right)$ demonstrates a $100 \%$ detection, in $\mathrm{P}_{3}\left(\mathrm{P}_{4}\right)$, only $40 \%$ of the subjects show such estimate higher than the critical value. Small differences were found however between homologue leads which would indicate inter-hemispheric symmetry. For the occipital leads, considering the $95 \%$ confidence limits, one can state that the strength of driving response in subjects \# 9 and 10 is significantly higher than that for the other subjects. It is also noted that for both subjects the photic driving response is higher in $\mathrm{P}_{3}$ than in $\mathrm{P}_{4}$.

\section{DISCUSSION}

The application of the Spectral F-Test allows detecting responses not only at the fundamental IPS frequency of $6 \mathrm{~Hz}$ but also at higher harmonics including the frequencies within the upper beta and lower gamma bands. Moreover, using the alternative hypothesis of the presence of response and the $95 \%$ confidence interval it is possible to apply this statistical technique as an indicator of the strength photic driving response. Thus, SFT can be used to compare the strength of the driving response in distinct brain regions, at diffe rent frequencies in the same location and in diff e rent subjects, e.g. controls and patients. This capacity (ability) can give certain advantage to SFT over spectral peak amplitude measurement ${ }^{4}$ since the former in contrast to the latter deals with changes based on statistical criterion (significance level).

The curves obtained for the probability of detecting a spectral change (which should reflect photic driving in the EEG during IPS) can provide import ant information in clinical application, such as the minimum data stretch necessary for a $95 \%$ detection rate in a signal with a given signal-to-noise ratio. Thus, for SNR close to zero, i.e. response and background with close amplitude-values, a minimum of 48 epochs should be used to provide $95 \%$ detection. On the other hand, for SNR close to $-2 \mathrm{~dB}$ (which reflects amplitude response nearly 1.6 times smaller than that of background EEG), this number should be doubled to maintain the same detection rate.

All these findings show a broad potential of the SFT application to the estimation of the EEG photic driving reactions, particularly in special experimental and clinical conditions which demand a finer sensitivity of the EEG characteristics to the functional states of the brain. It looks promising in the topographic approach to the study of the driving effects in the brain ontogenetic development, in the study of functional alterations in neurological and psychiatric diseases, for instance, etc. where it can improve a diagnostic value of the IPS functional test.

\section{REFERENCES}

1. Chatrian GE, Bergamini L, Dondey M, Klass DW, Lennox-Buchthal M, Petersen I. A glossary of terms most commonly used by clinical electroencephalographers. Electroenceph Clin Neurophysiol 1974;37: 538-548. 
2. Takahashi T. Activation methods. In Niedermeyer E, Lopes da Silva FH (eds). Electroencephalography: basic principles, clinical applications, and related fields. $4^{\text {th }}$ Ed. Baltimore: Williams \& Wilkins, 1999: 261-284.

3. Lazarev VV, Simpson DM, Schubsky BM, de Azevedo LC. Photic driving in the electroencephalogram of children and adolescents: harmonic structure and relation to the resting state. Braz J Medi Biol Res 2001; 34:1573-1584.

4. Lazarev VV, Infantosi AFC, Valencio-de-Campos D, de Azevedo LC. Topographic aspects of photic driving in the electroencephalogram of children and adolescents. Braz J Medi Biol Res 2004;37:879-891.

5. Miranda de Sá AM, Infantosi AF. Evaluating the entrainment of the alpha rhythm during stroboscopic flash stimulation by means of coherence analysis. Med Eng Phys 2005;27:167-173.

6. Simpson DM, Tierra-Criollo CJ, Infantosi AFC. Objective response detection in an electroencephalogram during somatosensory stimulation. Ann Biom Med Eng 2000;28:621-698.

7. Ramos EG, Zaeyen EJB, Simpson DM, Infantosi AFC. Detecção de res- posta auditiva no EEG de crianças utilizando técnicas no domínio da freqüência. Rev Bras Eng Biomed 2000;16:127-137.

8. Shumway RH. Applied statistical time series analysis. London: Prentice Hall, 1988:77-84.

9. Kay SM. Fundamentals of statistical signal processing: detection theory. New Jersey: Prentice-Hall, 1998;2:60-93.

10. Miranda de Sá AMFL, Infantosi AFC. A coherence-based technique for evaluating the degree of synchronism in the EEG during sensory stimulation. Rev Bras Eng Biome 2002;18:39-49.

11. Akaike $H$. On the statistical estimation of the frequency response function of a system having multiple input. Ann Inst Stat Mth 1965;17: 185-210.

12. Brillinger DR. Time series: data analysis and theory. San Francisco: Holden-Day, 1975.

13. Infantosi AFC, Lazarev VV, Valencio-de-Campos D. O teste F espectral na detecção de resposta no EEG durante fotoestimulação intermitente. Anais do XVIII Congresso Brasileiro de Engenharia Biomédica 2002;5: 497-501. 